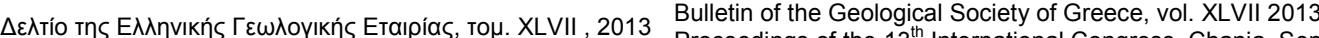

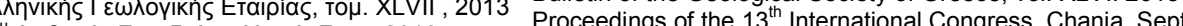

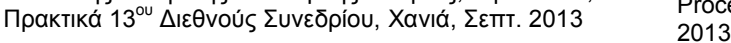

\title{
SAFETY ASSESSMENT AND REMEDIAL MEASURES DESIGN FOR AN EXTENSIVE ROCKFALL ALONG THE MAIN ROAD TO KIMI, EAST EUBOEA, GREECE
}

\author{
Loupasakis C. ${ }^{1}$, Lalos G. ${ }^{1}$ and Rozos D. ${ }^{1}$ \\ ${ }^{1}$ Laboratory of Engineering Geology and Hydrogeology, School of Mining and Metallurgical \\ Engineering, National Technical University of Athens, 9 Iroon Polytechneiou, Athens, Greece \\ cloupasakis@metal.ntua.gr,rozos@metal.ntua.gr
}

\begin{abstract}
The steep morphology and the intense tectonic fragmentation of the mountainous areas of Greece combined with the dense road network create conditions favorable for the manifestation of rockfalls. Numerous events are recorded through the years, some of them causing injuries or even worse loss of lifes.

The rockfall that took place along the Kimi - Platana - Paralia provincial road on August 2008, was studied in detail and is presented in the current paper. The rock detachment area was defined $200 \mathrm{~m}$ away and at an altitude of $140 \mathrm{~m}(130 \mathrm{~m}$ higher from the road), while the rock pieces detached had a maximum volume of $4 \mathrm{~m}^{3}$. The final consequences were two crashed cars and a heavily injured civilian.

The causual factors as well as the proposed remedial measures, estimated by the use of RocFall by Rockscience Ltd., are described in detail. Furthermore, the temporary remedial measures applied by contractors are evaluated, pointing their defects.
\end{abstract}

Key words: Marl formations, RocFall Software, statistical analysis, risk assessment.



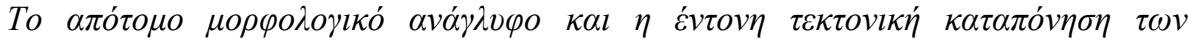

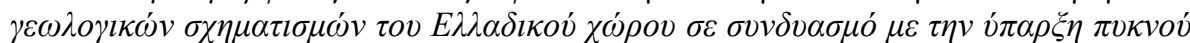

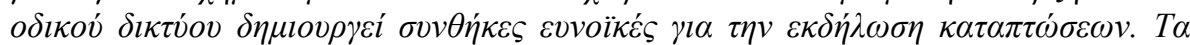

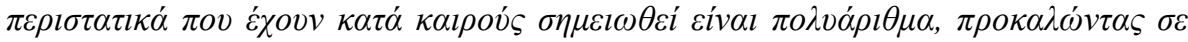

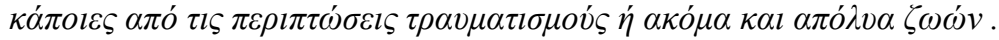

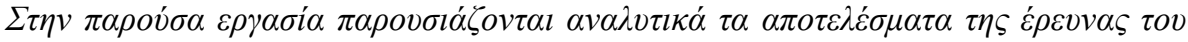

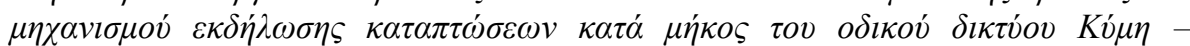

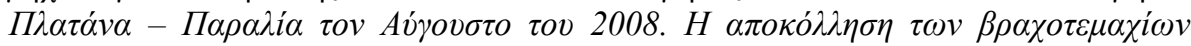

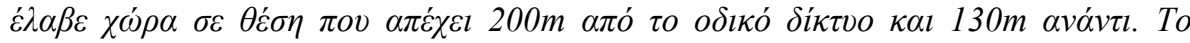

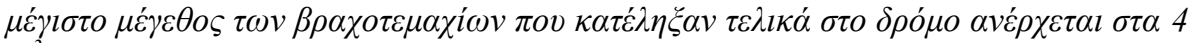

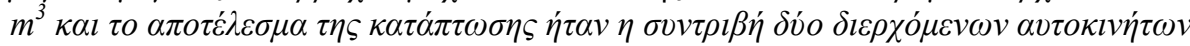

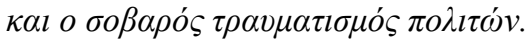

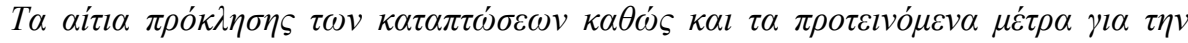

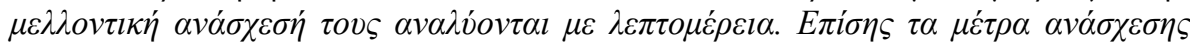

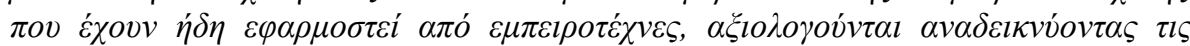

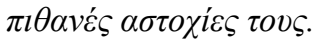

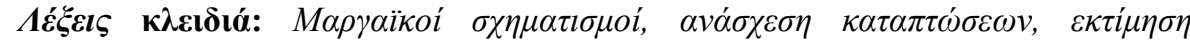
$\kappa \imath v \delta v ́ v o v ~ \kappa \alpha \tau \alpha \pi \tau \omega ́ \sigma \varepsilon \omega v, \sigma \tau \alpha \tau \imath \sigma \tau \iota \kappa \eta ́ ~ \alpha \nu \alpha ́ \lambda v \sigma \eta$.

XLVII. No $3-1739$ 


\section{Introduction}

The continuous urbanization and development in landslide-prone areas led to the manifestation of an increasingly high landslide activity during the last decades in Greece. Among the failures, rockfalls hold a leading role acting rapidly, without any former notification, causing serious socioeconomic consequences (Loupasakis et al, 2010; Antoniou \& Lekkas, 2010; Christaras et al, 2010). Unfortunately, sometimes beside the significant economic losses, they cause serious injuries or even worse loss of lives.

The case study presented through this paper refers to a failure that took place on August 13, 2008, at the provincial road connecting Paralia village with Kimi seaport. Kymi is a town at the eastern central part of Euboea Island and the above mentioned road is highly important as it is the main artery leading to the harbour.

The currently examined failure along this road causes up to now serious socio-economic consequences as the remedial measures applied are temporary and incomplete. The unobstructed road connection with the harbour cannot be accomplished, as the slope still presents serious stability problems. Besides the abovementioned long lasting problems, the failure left behind a civilian with permanent disability, as the rocks crashed two cars passing through at the time (Figure 1).

This paper focuses on the description of failure as well as on the design of the appropriate remedial measures. Furthermore, the temporary remedial measures applied up to now by contractors are evaluated, pointing at their defects. All abovementioned Rockfall simulations were conducted by using RocFall by Rockscience Ltd. This is a statistical analysis program designed for rockfalls risk assessment (Rocscience, 2002).
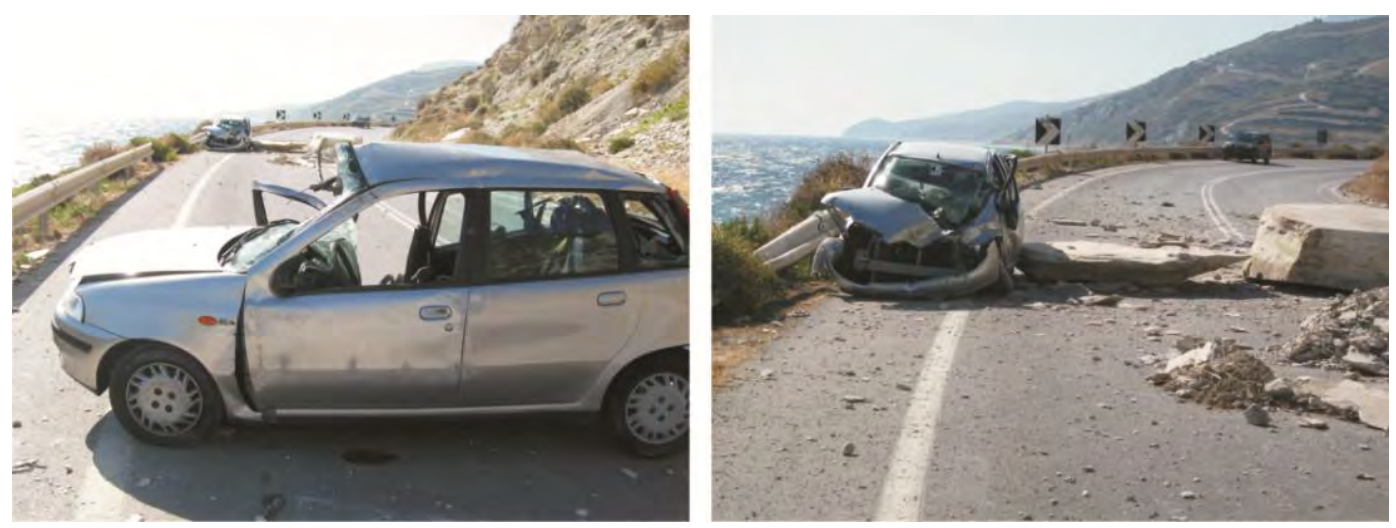

Figure 1 - View of the road, right after the Rockfall took place. The oversize blocks as well as the crashed cars are presented.

\section{Historical Background of the Failure}

As mentioned above, the examined failure took place on August 13, 2008, at 20:30 approximately, at the provincial road connecting Paralia village with Kimi seaport, $900 \mathrm{~m}$ from Paralia village. The rock seeder (rock detachment area) was defined $200 \mathrm{~m}$ away and at an altitude of $140 \mathrm{~m}(130 \mathrm{~m}$ higher from the road) (Figures $2 \& 3$ ). The marly limestone rock pieces were detached from the upper parts of the slope. The majority of the limestones 'rectangular rock pieces slid a few tens of meters from the seeders and stopped without causing any damages. Unfortunately a few oversized pieces, reaching to a maximum volume of $4 \mathrm{~m}^{3}$, rolled down the slope and finally reached the road. The rock pieces reached the road with an enormous kinetic energy causing the aforementioned results. 


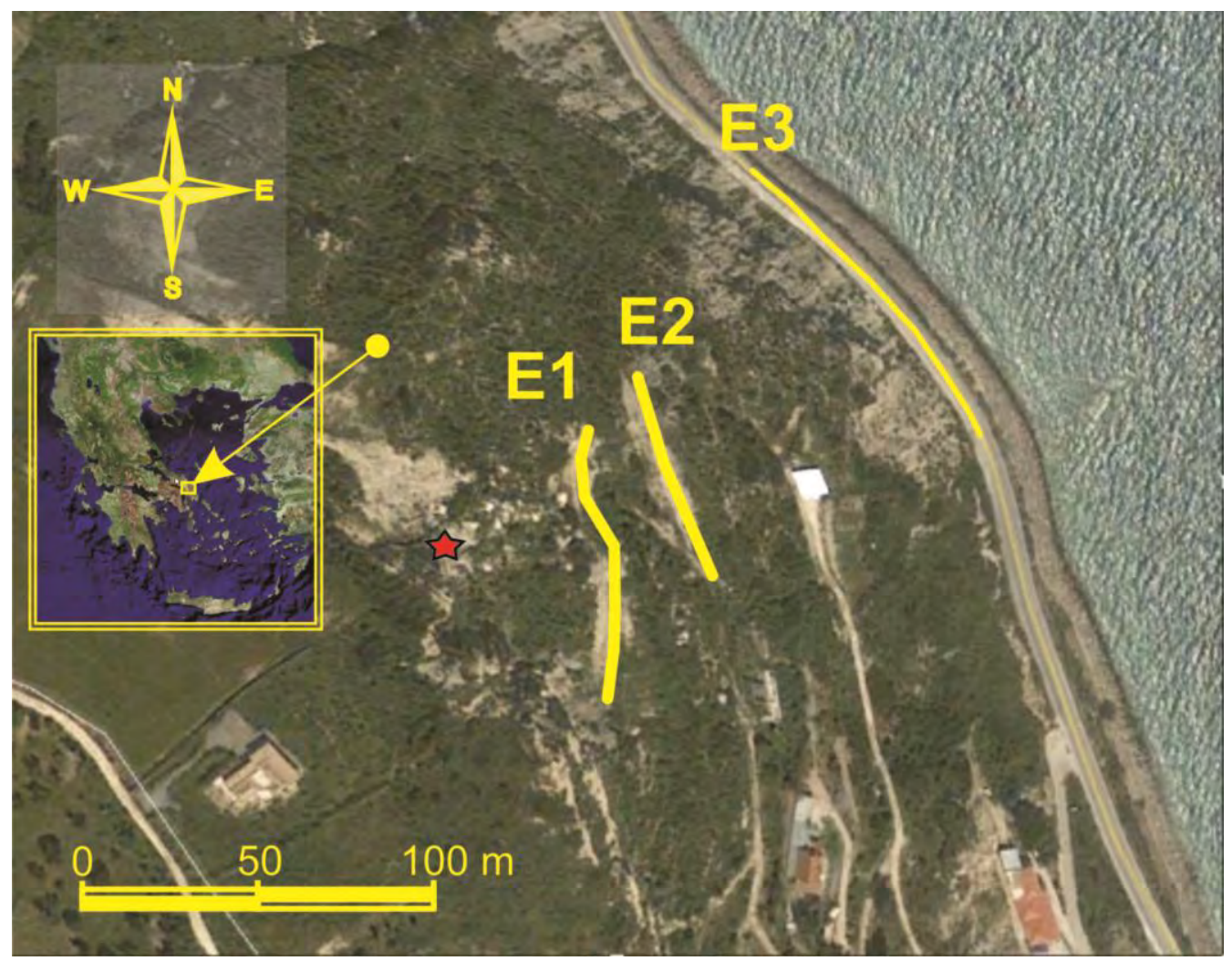

Figure 2 - Location map of the study area. The star indicates the rock detachment area of the August 13, 2008 failure. The lines E1 and E2 indicate the position of the soil embankments constructed over the slope and line $\mathrm{E} 3$ the position of a temporary embankment installed in the middle of the road, with gravel filled big bags.

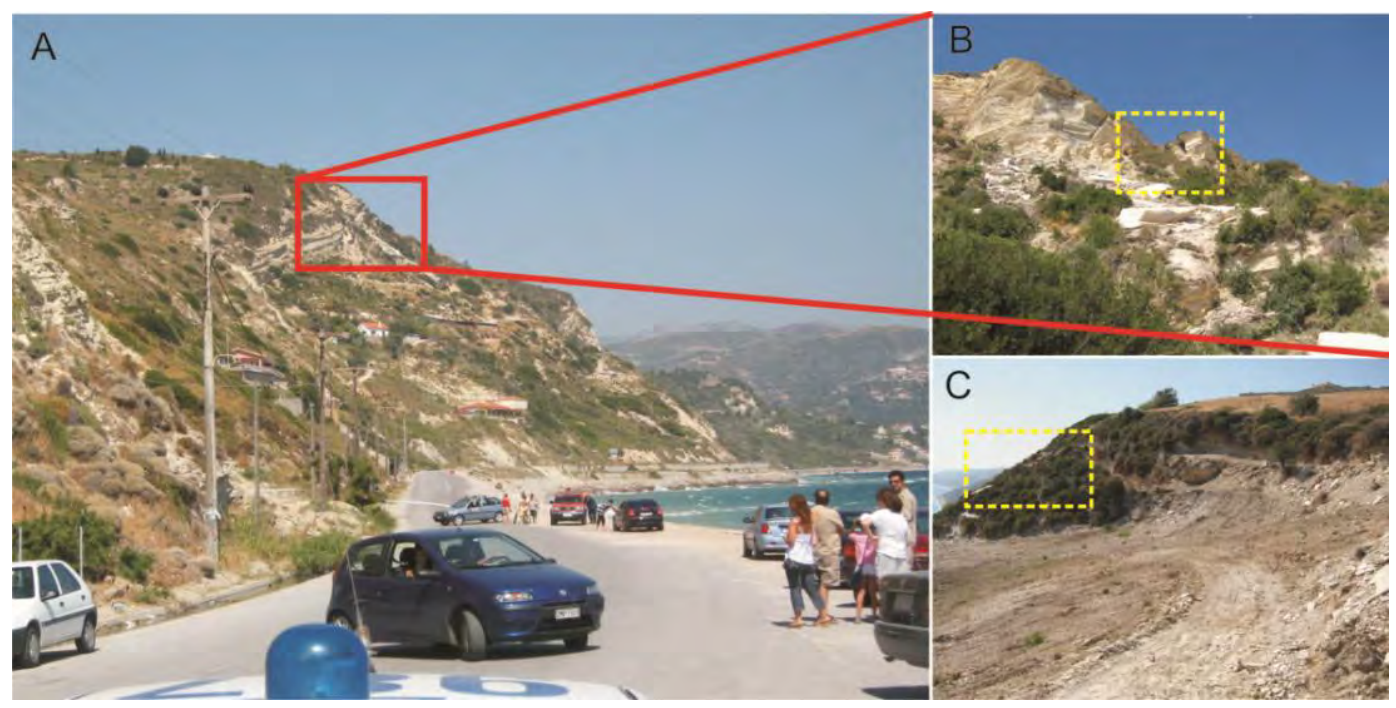

Figure 3 - View of the examined slope. The rock detachment area is indicated on picture A. Picture B provides a closer view of the detachment area. Picture $C$ presents the earth moving works that took place before the failure at the crest of the slope. 
The following days, and before conducting a complete geotechnical study, a temporary embankment was installed in the middle of the road (Figures $2 \& 4 \mathrm{~A}, \mathrm{~B}$ ). This $2 \mathrm{~m}$ high embankment (E3 at Figure 2) was constructed by two series of big bags filled with gravels, aiming to provide a safety at the external lane of the road, preventing the complete blocking of the traffic. This temporary embankment still remains there as none ever decided to remove it. Figure 4A, B proves that although it was installed based on empirical estimations, it operated perfectly during the years, trapping several rock block and protecting the external lane of the road.

Besides the above mentioned embankment, extensive earth moving works took place on the slope aiming to modify its morphology, forming a complex of ditches and embankments, E1 \& E2, as remediation measures (Figures $2 \& 4 C, D$ ). This works took place after the installation of the E3 temporary embankment by contractors appointed by the municipality. Despite all these works the temporary embankment $\mathrm{E} 3$ was not removed at the end.

At the same period, extensive emendatory earth moving works took place around the rock detachment area. The detachment area was located right next to an extensive excavation (Figure 3C) that was under construction at the period of the failure. So in order to prevent farther failures from the same location several rock blocks were moved from the site.

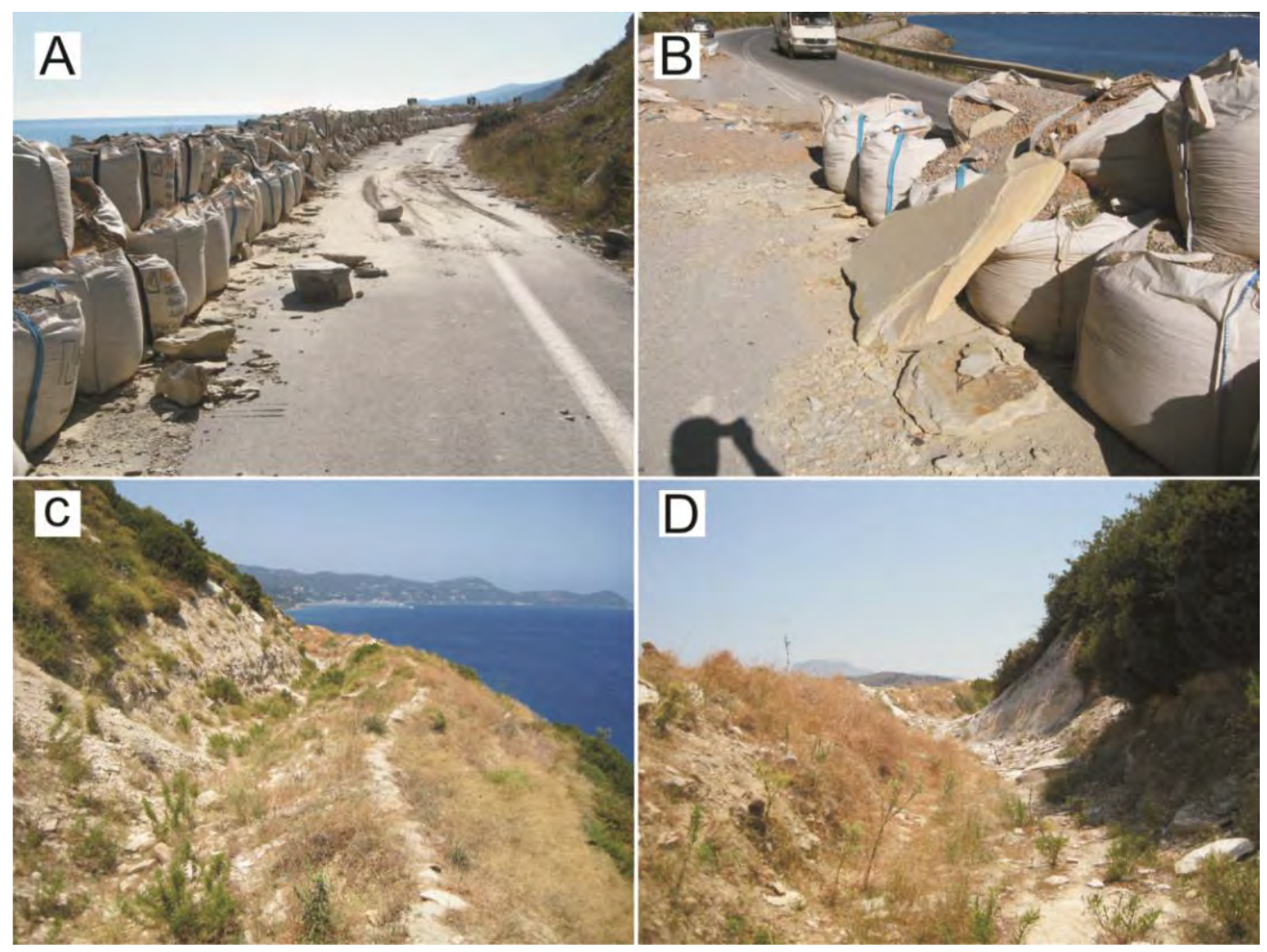

Figure 4-A \& B Photos present the embankment, E3, constructed in the middle of the road.

The numerous trapped rock blocks prove the effectiveness of the embankment, initially constructed as a temporary protection measure. $C \& D$ photos present the embankments, E1 and E2.

\section{Geological Setting}

The study area has a steep relief and the road connecting Paralia village with Kimi seaport is constructed along the coast line. The neighbouring slopes present numerous failures and several 
studies concerning their stability have been conducted the last years (Apostolidis \& Pogiatzi, 1996; Koutsouveli \& Milonaki, 1996, Koumantakis et. al, 2007).

The wider study area consists of pre-alpine rocks, alpine formations, of the Pelagonian geotectonic zone, and post alpine Neogene and Quaternary deposits (Katsikatsos et al. 1986; Mettos et al. 1991; Serelis et al. 2004). The geological formations occupying the wider study area are: (a) Quaternary deposits (coastal, alluvial, terra rossa, fans ech), (b) Neocene sediments (marls- clayey marls, marly limestones and cohesive clastic formations), (c) Volcanic rocks, (d) flysch formations, (e) limestones, (f) shist-cherts, (g) bauxite bodies and (h) metamorphic rocks.

The examined slope consists of Neogene formations, clayey marls and calcitic marls to marly limestones. The clay marls occupy the lower parts of the slope and the marly limestones the upper. The morphology of the slope is highly affected by its geological structure. As presented at figure $3 \mathrm{~A}$, the lower parts, occupied by the relatively soft and erodible clayey marls, appear gentler inclination and the upper, occupied by the hard calcitic marls to marly limestones, much steeper, forming vertical slopes. Furthermore, the differences on the erodibility of the two formations lead to the underexcavation of the marly limestones, forming sections with overhanging blocks.

\section{Rockfall Risk Assessment}

The evaluation of the stability conditions was established by analysing six cross sections along the slope (figure 5). The selected cross sections cover the entire unstable slope section, including all possible rock detachment areas. By using Rockfall Software each cross section was analysed by considering two different profiles, the natural slope profile as well as the new profile formed after the construction of the embankments (Figure 5). Two rock detachment areas (seeders) have been defined on each cross section, the upper seeder, located along the crest of the slope and the lower seeder, located at the steep slope section attached on the side of the road. Defining the initial conditions, the starting velocity of the rock blocks was set $0 \mathrm{~m} / \mathrm{s}$ and their mass was set to range from 20 to $2500 \mathrm{kgr}$, covering the majority of the blocks located on site.

Altering the friction angle value of the slope surface - rock block interface (Phi), two different project scenarios were defined. According to the first scenario the friction angle gets zero value, signifying that the rock blocks roll down the slope. At the second scenario, the friction angle gets values reflecting the properties of the formation occupying the slope surface. The assignment of friction angle values indicates that the rock blocks slide on the slope surface, decelerating due to the friction.

Considering the slope surface material properties four different types of materials were defined, as follows:

a) Marly limestones (calcitic marls to marly limestones): occupying the crest of the slope, the upper seeder.

b) Marls: occupying the lower section of the slope right next to the road, the lower seeder.

c) Talus cover: extending at the feet of the seeders, formed by the detached rock blocks.

d) Soil with vegetation: occupying the gentle sections of the slope. Practically this material is the vegetated weathering mantle of the marls.

e) Asphalt: occupying the road

The properties assigned to the abovementioned materials were estimated by in situ tests or selected from bibliographic sources (Giani, 1992; Rocscience, 2002; Asteriou, 2012) (Table 1).

The numerous rockfall simulations conducted according to the above described scenarios have been evaluated by examining the kinetic energy (Total, Translational, and Rotational) envelopes as well as the velocity and bounce height envelopes.

XLVII, No $3-1743$ 

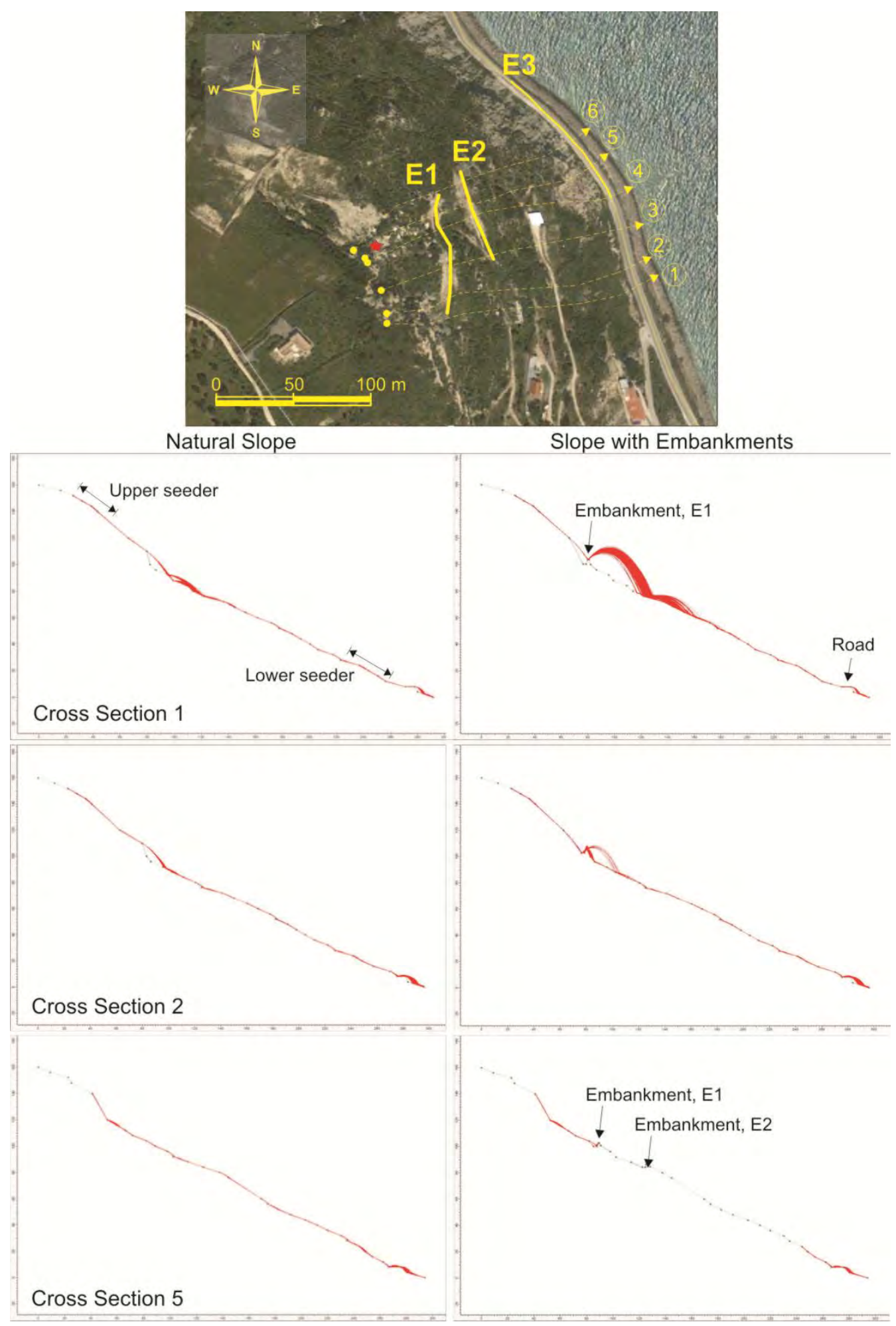

Figure 5 - The Satellite pictures, taken from Google Earth, points the six cross sections selected along the slope for the simulation of the rockfalls. Characteristic examples of simulation results are presented in selected cross sections. 
Table 1 - Material properties (Giani, 1992; Rocscience, 2002).

\begin{tabular}{|l|l|l|l|l|}
\hline \multicolumn{1}{|c|}{ Material Name } & \multicolumn{1}{|c|}{$\begin{array}{c}\mathbf{R n}^{*} \\
(\mathbf{m e a n} / \mathbf{s d})\end{array}$} & \begin{tabular}{c}
\multicolumn{1}{|c|}{$\mathbf{R t}^{\star *}$} \\
$(\mathbf{m e a n} / \mathbf{s d})$
\end{tabular} & \multicolumn{1}{|c|}{$\begin{array}{c}\text { Phi }\left(^{\circ}\right) \\
(\mathbf{m e a n} / \mathbf{s d})\end{array}$} & $\begin{array}{c}\left.\text { Roughness } \mathbf{(}^{\circ}\right) \\
(\mathbf{s d})\end{array}$ \\
\hline Marly limestone & $0.40 / 0.02$ & $0.85 / 0.02$ & $30^{\circ} / 2^{\circ}$ & $2^{\circ}$ \\
\hline Marl & $0.35 / 0.02$ & $0.80 / 0.02$ & $30^{\circ} / 2^{\circ}$ & $2^{\circ}$ \\
\hline Talus cover & $0.32 / 0.04$ & $0.82 / 0.04$ & $30^{\circ} / 2^{\circ}$ & $1^{\circ}$ \\
\hline Soil with vegetation & $0.30 / 0.04$ & $0.80 / 0.06$ & $30^{\circ} / 2^{\circ}$ & $1^{\circ}$ \\
\hline Asphalt & $0.40 / 0.04$ & $0.92 / 0.04$ & $30^{\circ} / 2^{\circ}$ & $0^{\circ}$ \\
\hline
\end{tabular}

*Rn: Normal coefficient of restitution, the ratio of the outgoing velocity (normal to the surface) to the incoming velocity (normal to the surface).

$* *$ Rt: Tangential coefficient of restitution, the ratio of the outgoing velocity (tangential to the surface) to the incoming velocity (tangential to the surface)

The simulations proved that the embankments E1 and E2 improved the safety conditions of the slope but unfortunately they did not eliminate the risk. The outcomes of the simulations can be listed as follows:

Considering the natural slope

a) The majority of the rock blocks rolling from the upper seeder reach the road. The kinetic energy values at the level of the road are presented in Table 2.

b) All the rock blocks sliding from the upper seeder stop covering a maximum distance of $100 \mathrm{~m}$, depending on the morphology. They never reach the road.

c) All the rock pieces rolling from the lower seeder reach the road. The fact that the lower seeder does not bear large pieces reduces the risk and makes the necessary remedial measures simpler.

d) Due to the gentle morphology of the lower southeastern part of the slope, the rock blocks sliding from the lower seeder never reach the road (cross sections $1-3$ ). On the contrary the pieces sliding from the rest of the lower seeder (cross sections $4-6$ ) reach the road with a small kinetic energy (Table 2).

Considering the slope with the embankments

e) All the rock block sliding or rolling from the northwestern part of the upper seeder (cross sections $3-6$ ), get blocked by the embankments. The results are the same with the pieces sliding from the rest of the upper seeder (cross sections $1 \& 2$ ).

f) The results are completely different with the blocks rolling form the southeastern part of the upper seeder (cross sections $1 \& 2$ ). This particular section is protected only by the embankment E1. As presented in Figure 5, embankment E2 does not extent so far south. The simulations saw that the rocks hit the embankment, pass over it and continue their course to the road. Furthermore, as presented in table 2, the blocks bouncing on the embankment accelerate, hitting the road with a little higher kinetic energy.

Concluding, the embankments, E1 and E2, protect the road from the rock blocks detached from the northwestern part of the upper seeder (cross sections 3-6). On the contrary, they make the safety conditions at the rest of the seeder (cross sections $1 \& 2$ ) worse, accelerating the rolling blocks. Furthermore, the road stays completely unprotected from the lower seeder. 
Table 2 - Prominent kinetic energy values

\begin{tabular}{|c|c|c|c|c|}
\hline \multirow{2}{*}{$\begin{array}{c}\text { Cross } \\
\text { section } \\
\text { no. }\end{array}$} & \multirow{2}{*}{$\begin{array}{l}\text { Natural slope - rock } \\
\text { blocks rolling from } \\
\text { the upper seeder - } \\
\text { kinetic energy at the } \\
\text { level of the road }(\mathrm{Kj}) \\
\text { (max / min) }\end{array}$} & \multicolumn{2}{|c|}{$\begin{array}{l}\text { Slope with embankments - } \\
\text { rock blocks rolling from the upper seeder }\end{array}$} & \multirow{2}{*}{$\begin{array}{l}\text { Natural slope - } \\
\text { rock blocks sliding } \\
\text { from the lower } \\
\text { seeder - kinetic } \\
\text { energy at the level } \\
\text { of the road (Kj) } \\
\text { (max / min) }\end{array}$} \\
\hline & & $\begin{array}{l}\text { kinetic energy at the } \\
\text { level of the road }(\mathrm{Kj}) \\
\text { (max / } \mathrm{min})\end{array}$ & $\begin{array}{l}\text { kinetic energy at } \\
\text { the level of the em- } \\
\text { bankments }(\mathrm{Kj}) \\
(\max / \mathrm{min})\end{array}$ & \\
\hline 1 & $175 / 2$ & $185 / 1$ & pass over & no rock blocks \\
\hline 2 & $300 / 2.8$ & $330 / 2.5$ & $250 / 2.1$ & no rock blocks \\
\hline 3 & $300 / 2.4$ & no rock blocks & $220 / 1.8$ & no rock blocks \\
\hline 4 & $350 / 2.8$ & no rock blocks & $310 / 2.4$ & $40 / 0.3$ \\
\hline 5 & $310 / 2.5$ & no rock blocks & $280 / 2.2$ & $50 / 0.4$ \\
\hline 6 & $600 / 4.7$ & no rock blocks & $156 / 1.5$ & $223 / 1.8$ \\
\hline
\end{tabular}

\section{Remediation Measures Design}

In order to secure the road and safely remove the "temporary" embankment E3, a few additional remedial measures have to be constructed. The new remedial measures must block the boulders passing over E1 embankment, at the cross sections 1 and 2, and also secure the lower seeder.

The rockfall simulations indicated that the rock blocks bouncing over the embankment can be stopped by installing a new embankment, EN, at the location indicated in Figure 6 . At this particular location the rock pieces move with a reduced kinetic energy and their bouncing height is decreased (Table 3). The current embankment can be constructed, as the previous embankments, by compacted soil materials or even better by reinforced soil materials. The reinforcement of the soil material can be accomplished by the use of geotextiles. The impact catchment face of the embankment can be protected by installing gabion blocks, gabion like wall face or impact catchment bags (Figure 7). Considering the bounce height (max $1.4 \mathrm{~m})$ and the radius $(0.5 \mathrm{~m})$ of the boulders, an embankment $3 \mathrm{~m}$ high is sufficient for the current position. Furthermore considering that reinforced embankments can stand an impact force up to several thousand $\mathrm{Kj}$, this, low-price, solution can be sufficient even in the case of a bigger block rockfall. Most sophisticated and at the same time most expensive, pathetic remedial measures, suitable for the current location, are the rockfall fences.
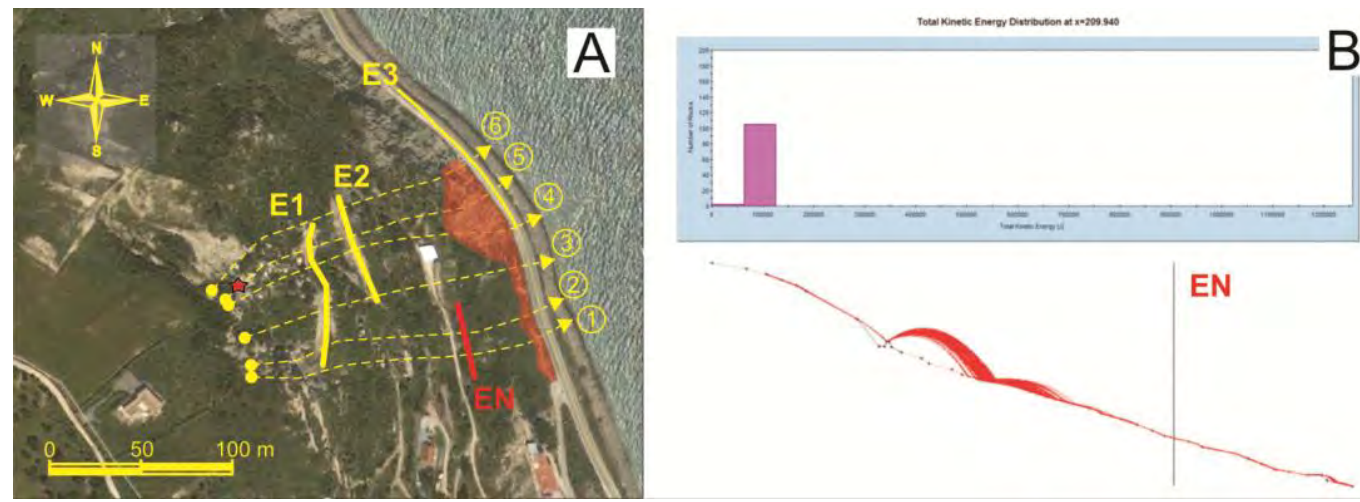

Figure 6-A) Arrangement of the proposed extra remediation measures. B) The kinetic energy envelope at the location of the EN embankment. 
Table 3 - Maximum kinetic energy and bouncing height at the location proposed for the installation of the new embankment, EN.

\begin{tabular}{|l|l|l|}
\hline Cross section no. & Kinetic energy $(\mathbf{K j})$ & Bounce height $(\mathbf{m})$ \\
\hline 1 & 130 & 1.4 \\
\hline 2 & 210 & 1.3 \\
\hline
\end{tabular}

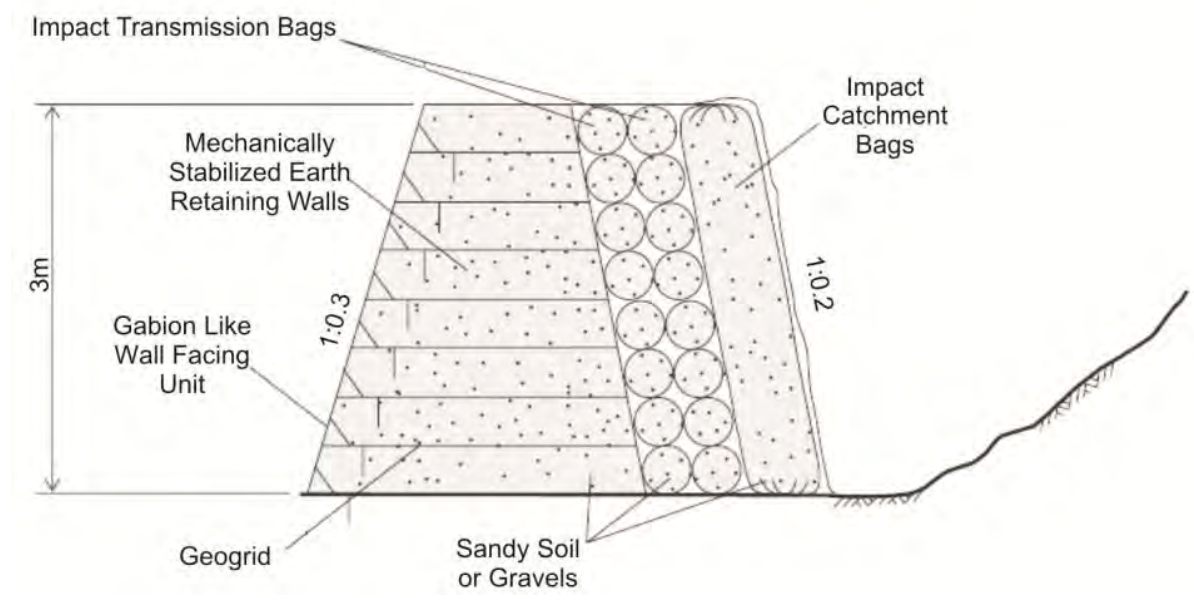

Figure 7 - A typical cross section of a reinforced soil embankment, containing all possible combinations of geomaterials (geogrids, gabion like wall face and impact catchment bags) (modified from Yoshida, 1999).

The lower seeder can be secured by installing a uniaxial double-twist wire mesh covering the entire lower seeder. Double-twist mesh is the ideal solution due both to its flexibility in every direction and the fact that gaps in the mesh are avoided in the event of accidental breakage of some wires. The wire mesh must be suspended by using fixed anchorage at the top and removable anchorage at the bottom, to facilitate during the maintenance. The mesh must be kept free along the slope, letting the rock masses fall to the base of the slope but always keeping them between the rock slope and the barrier mesh. Before the installation of the mesh all individual hanging rock blocks must be removed. The installation of the wire mesh besides the obvious support, forces detached rock pieces to slide instead of rolling. So it does not allow them to obtain substantial kinetic energy.

At this point it should be noted that, the exact location or the extension of the proposed remedial measures, presented in Figure 6, can be slightly modified or corrected by using a new custommade detailed topographic map. The current simulations as well as the proposed measures were designed by taking under consideration the topographic maps of the Hellenic Military Geographical Service, at a scale of 1:5000.

\section{Conclusions}

The current case study provides a combination of new additional remediation measures able to secure this particular slope at the provincial road connecting Paralia village with Kimi seaport. These measures incorporate the existing embankments decreasing the cost of the additional constructions. 
Besides its practical value, this study indicates the necessity of taking under consideration the stability conditions of natural rock slopes when constructions are planned. At this particular case study the stability conditions were ignored both during the pre failure period, when the extensive excavation took place at the crest of the slope, as well as during the construction of the remedial measures, after the rockfall. Unfortunately these actions have already caused and will farther generate unacceptable economic loss.

\section{References}

Antoniou A. and Lekkas E. 2010. Rockfall susceptibility map for Athinios port, Santorini Island, Greece, Geomorphology, 118, pp. 152-166.

Apostolidis E. and Pogiatzi E. 1996. Geological study and mapping along the national road network of Paralia Kimis - Platana - Stomio. Unpublished technical report, IGME, Athens.

Asteriou P., Saroglou H. and Tsiambaos G. 2012. Geotechnical and kinematic parameters affecting the coefficients of restitution for rock fall analysis, International Journal of Rock Mechanics \& Mining Sciences, Vol. 54, pp. 103-113.

Christaras B., Papathanassiou G., Vouvalidis K. and Pavlides S. 2010. Preliminary results regarding the rock falls of december 17, 2009 at Tempi, Greece, Proceedings of the 12th International Congress of the Geological Society of Greece, Patras.

Giani G.P. 1992. Rock slope stability Analysis. Balkema, Roterdam.

Katsikatsos G., Migiros G., Triantaphyllis M. and Mettos A. 1986 Geological structure of Internal Hellenides (E. Thessaly-SW Macedonia-Euboea-Attica-Northern Cyclades Islands and Lesvos), IGME, Geol. \& Geoph. Res., Special Issue, pp. 191-212).

Koutsouveli A. and Milonaki J. 1996. Geotechnical study of the road network "Paralia Kimis Platana - Stomio“ S. Euboea, Unpublished technical report, IGME, Athens.

Koumantakis J., Rozos D., Markantonis K., Ilia J. and Tsagaratos P. 2007. Landslide phenomena at Kimi municipality area, Unpublished work $121 \mathrm{pp}$. Athens.

Loupasakis C., Galanakis D. and Rozos D. 2010. Rock Slope Stability Problems in Natural Sightseeing Areas - An Example From Arvanitia, Nafplio, Greece, Proceedings of the 12th International Congress of the Geological Society of Greece, Bulletin of the Geological Society of Greece vol. XLIII, No 3, pp. 1465-1473.

Mettos A., Rondogianni Th., Papadakis I., Paschos P. and Georgiou C. 1991. New data on the geology of the Neogene deposits of N. Euboea, Bulletin of the Geological Society of Greece $X X V$ (3), pp. 71-83 (in Greek).

Serelis K., Gartzos E. and Tsaousidou P. 2004. Study of the wall rock alteration occurring in ultramafic rocks hosting magnesite deposits, Euboea, Greece. Bulletin of the Geological Society of Greece vol. XXXVI, 377 - 386.

Yoshida H. 1999. Recent experimental studies on rockfall control, in: Masuya P, Labiouse V (eds) Proceedings of Joint Japan-Swiss Scientific Seminar on impact load by falling rocks and design of protection structures, Kanazawa (Japan), pp 69-78 